\title{
Limbah Loom Sebagai Alternatif Material Mebel \\ (Studi Kasus: PT House Of Rattan \& CV Property, Cirebon)
}

\author{
Susi Hartanto*1, Michael Limahelu*2, Kezia Natalie Sutanto*3 \\ ${ }^{1}$ Universitas Pelita Harapan \\ ${ }^{2}$ Program Studi Desain Produk, Fakultas Desain, Universitas Pelita Harapan
}

\begin{abstract}
Furniture factories are one of Cirebon's economy boosters as they employ many workers and produce numerous products for local and export orientation. As a consequence, this industry produces quite a large amount of waste, one of them is paper loom. Loom is a woven paper threads and metal wires which is used to wrap a number of furniture components, such as seat, backrest, etc. Case studies in 2 major factories in Cirebon, total loom waste reaches around 3 tonnes a month. This research provides recommendations of waste usage for furniture.
\end{abstract}

Keywords: loom, furniture, waste, Cirebon

\section{PENDAHULUAN}

Kota Cirebon merupakan salah satu area industri furniture yang cukup terkenal di Indonesia. Pabrik - pabrik banyak membuat produk untuk dalam dan luar negeri. Loom adalah material yang biasa digunakan untuk ayaman kursi rotan. Banyak orang mengira loom merupakan jenis rotan alami ataupun rotan sintetis. Sebenarnya loom terbuat dari kawat yang dibungkus kertas dan dianyam bersama sehingga menjadi gulungan bahan yang siap digunakan.

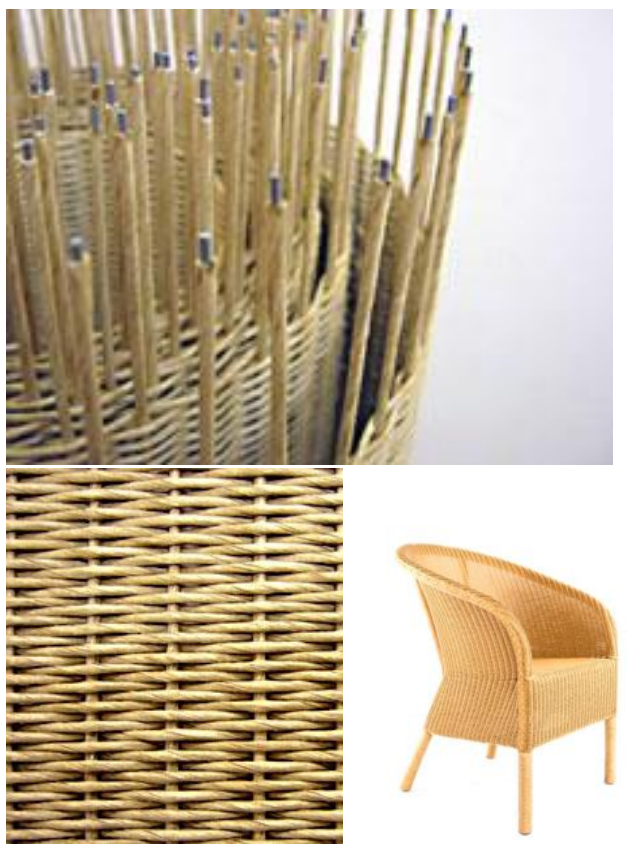

Gambar 1 Detail Bahan Loom dan Aplikasinya (Sumber : pinterest.com, 2017) 
Banyaknya produksi kursi yang mengunakan bahan loom membuat limbah loom semakin bertambah. Gulungan loom dipotong sesuai pola agar bisa membungkus furniture sesuai komponennya. Pada umumnya limbah loom hanya dibuang dan bagian kawat dikumpulkan dan menjadi kawat yang dijual secara kiloan, dan sisanya dibuang. Material ini memiliki tekstur yang menarik dan cukup saying jika dibuang begitu saja. Ukuran limbah loom beragam mulai dari, $10 \times 25 \mathrm{~cm}, 15 \times 40 \mathrm{~cm}$, sampai 60 $x 20 \mathrm{~cm}$.

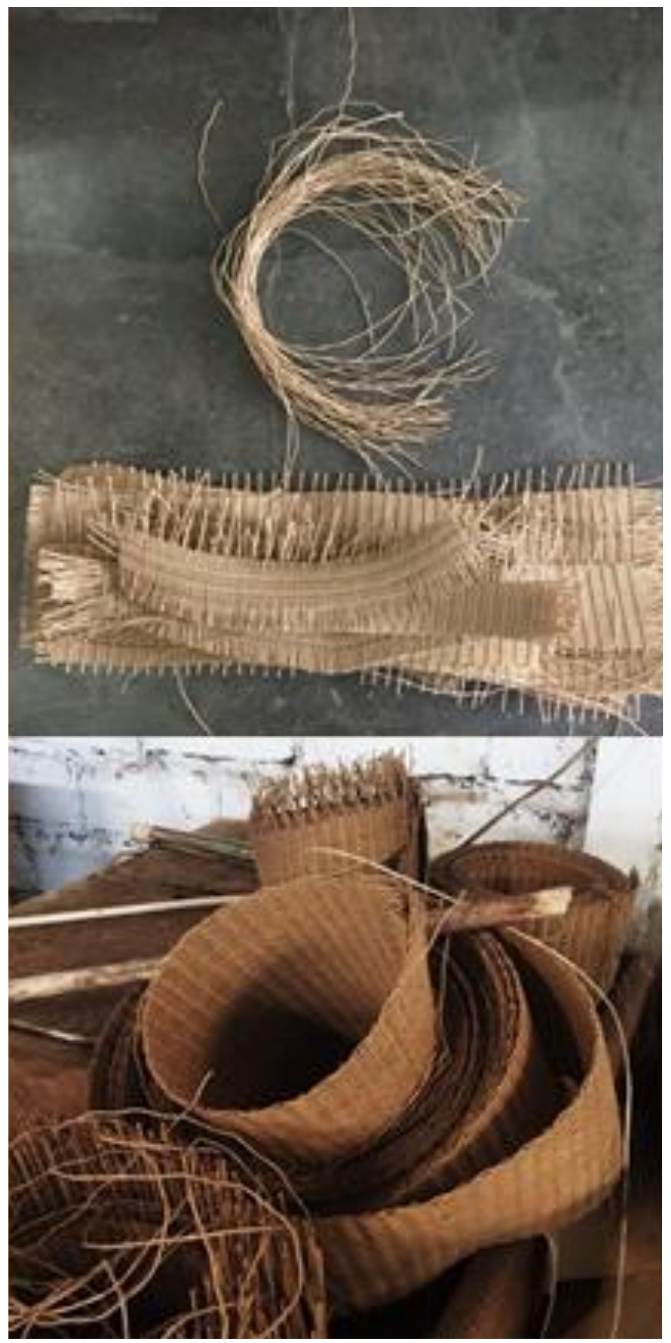

Gambar 2 Limbah Loom (Sumber : dokumentasi pribadi, 2017)

Adapun tujuan dari kajian ini adalah:
1. Mengurangi limbah loom dengan memberikan rekomendasi desain sehingga menjadi nilai tambah dari limbah tersebut.

2. Merekomendasikan rancangan produk yang cocok dengan karakteristik loom.

3. Mengambil studi kasus pabrik sehingga rekomendasi bisa langsung dimanfaatkan

\section{METODE PENELITIAN}

Berikut metode menghasilkan rekomendasi pemanfaatan loom:

1. Wawancara dan observasi PT House of Rattan \& CV Poperty, pakar loom, dan pakar desain produk.

2. Eksperimen limbah loom

\section{HASIL DAN ANALISIS}

Berikut hasil wawancara dengan PT House of Rattan (Pak Tatang \& Pak Sujut - pengalaman 17-20 tahun):

- Jumlah limbah loom sekitar 100-500 kg per bulan

- Harga ke supplier limbah: gratis

- Limbah loom tidak bisa disambung karena kendala konstruksi

- Ada beberapa cara mendaur ulang limbah loom dengan mengolahnya menjadi:

a. Kawat kiloan, dimana limbah di bakar habis dan hanya mensisakan bagian kawatnya saja, kawatnya itulah yang di daur ulang.

b. Pupuk, bagian kertas pada limbah loom dipotong sampai hancur dan dicampurkan dengan tanah, sedangkan bagian kawat menjadi kawat kiloan 
Berikut hasil wawancara dengan $\mathrm{CV}$ Property (Pak Agus - pengalaman 17 tahun):

- Jumlah limbah loom sekitar 1-3 ton per bulan

- Harga ke supplier limbah: Rp2.500/kg

- Material loom biasanya digunakan menjadi wadah (keranjang, tas), anyaman meja dan kursi. Untuk anyaman meja, biasa bagian atas menggunakan kaca agar permukaannya datar dan tekstur loom bisa tetap terlihat.

- Kelebihan loom dibandingkan rotan: loom lebih rapih dan stabil karena buatan pabrik, sedangkan rotan tidak stabil karena material dari alam

\section{Eksperimen Limbah Loom}

Dilakukan beberapa eksperimen untuk melihat metode terbaik apa dalam pemanfaatan limbah. Hasilnya ada 2 eksperimen yang paling memungkinkan dalam memaksimalkan penggunaan limbah loom tanpa menggunakan banyak material pendukung.

*Eksperimen 1

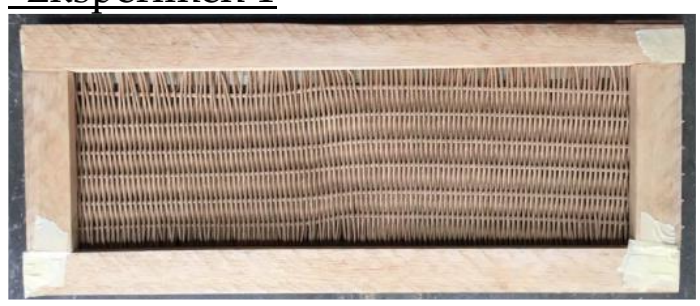

Gambar 3 Eksperimen 1 - Loom diberi rangka (Sumber : dokumentasi pribadi, 2017)

Kelebihan: bisa diaplikasikan untuk berbagai ukuran limbah loom, mulai dari yang kecil hingga besar Kekurangan:
- Permukaan yang besar membutuhkan lebih banyak rangka tambahan di tengah

- Jumlah material pendukung lebih banyak daripada limbahnya.

${ }^{*}$ Eksperimen 2

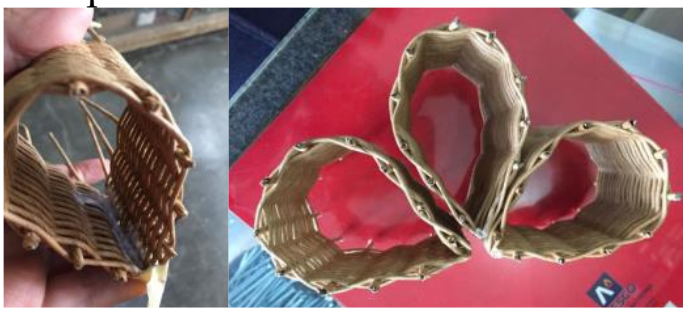

Gambar 4 Eskperimen 2 - Loom diberi lem \& dirangkai menjadi modul (Sumber : dokumentasi pribadi, 2017)

Kelebihan:

- Bentuk mengikuti karakter loom yang organik dan mudah dilekuk

- Rangka organik cocok menggunakan rotan yang juga adalah craftmanship unggul Cirebon

- Jumlah material pendukung lebih sedikit daripada limbahnya

Kekurangan: ada waktu tunggu untuk pengeringan lem

Karena hasil eksperimen 2 memperlihatkan lebih banyak kelebihan, maka metode ini yang dipakai untuk arahan awal rekomendasi desain nantinya. Kendala waktu tunggu pengeringan lem diselesaikan dengan menggunakan nail gun untuk produksi yang lebih cepat.

\section{Aplikasi Jenis Furniture}

Konstruksi meja yang relatif tidak banyak membuat tingkat kesulitan aplikasi limbah loom relatif rendah. Maka itu dibandingkan kursi, aplikasi 
pada meja dinilai lebih memungkinkan. Penyambungan antar rotan menggunakan nail gun lalu di ikat dengan pitrit (jenis rotan yang biasa digunakan sebagai anyaman). Konstruksi ini mengikuti proses pembuatan mebel pada

Rekomendasi Pemanfaatan Limbah Loom sebagai Coffee Table

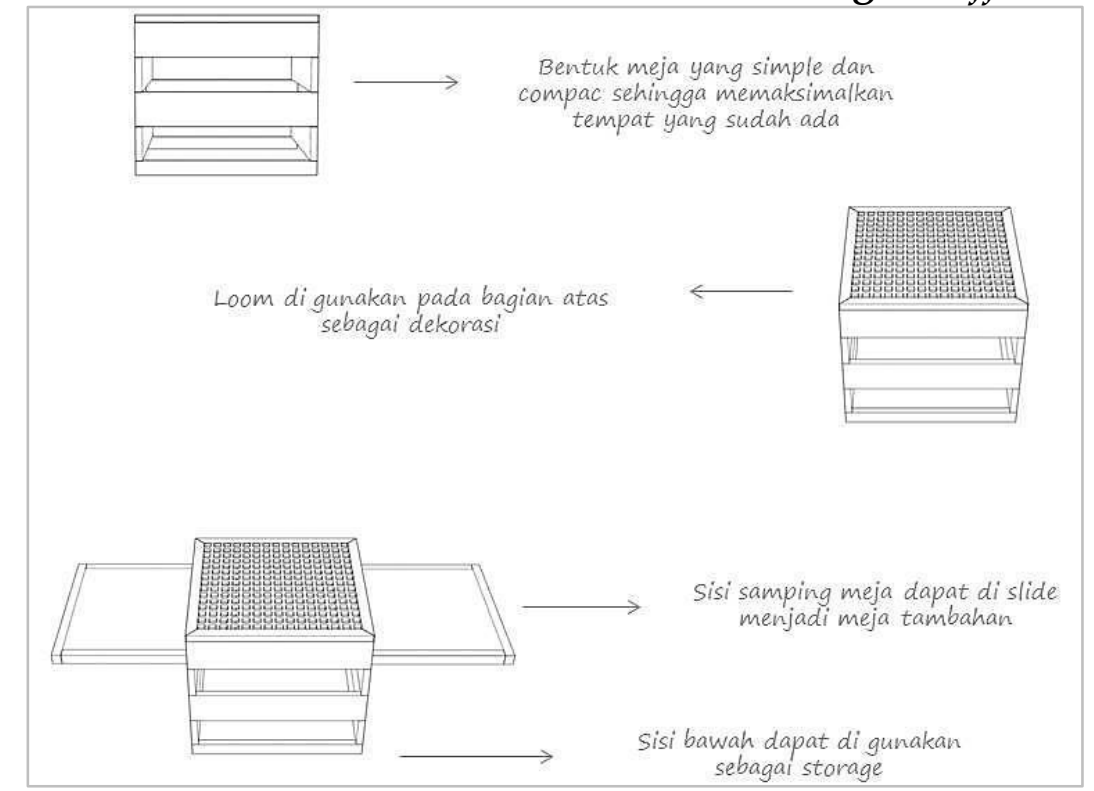

Gambar 3 Ilustrasi Pemanfaatan sebagai Meja 1 - Loom dalam rangka kayu (Sumber : dokumen pribadi, 2017)

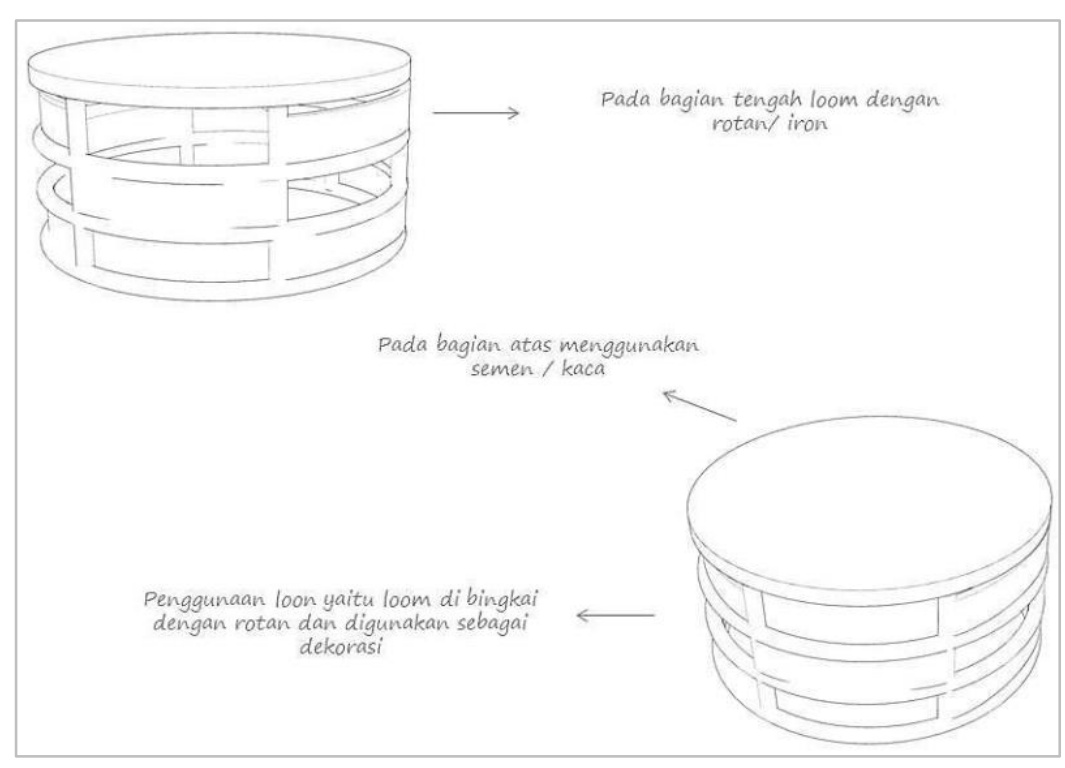

Gambar 4 Ilustrasi Pemanfaatan sebagai Meja 2 - Loom dalam rangka rotan (Sumber : dokumen pribadi, 2017) 


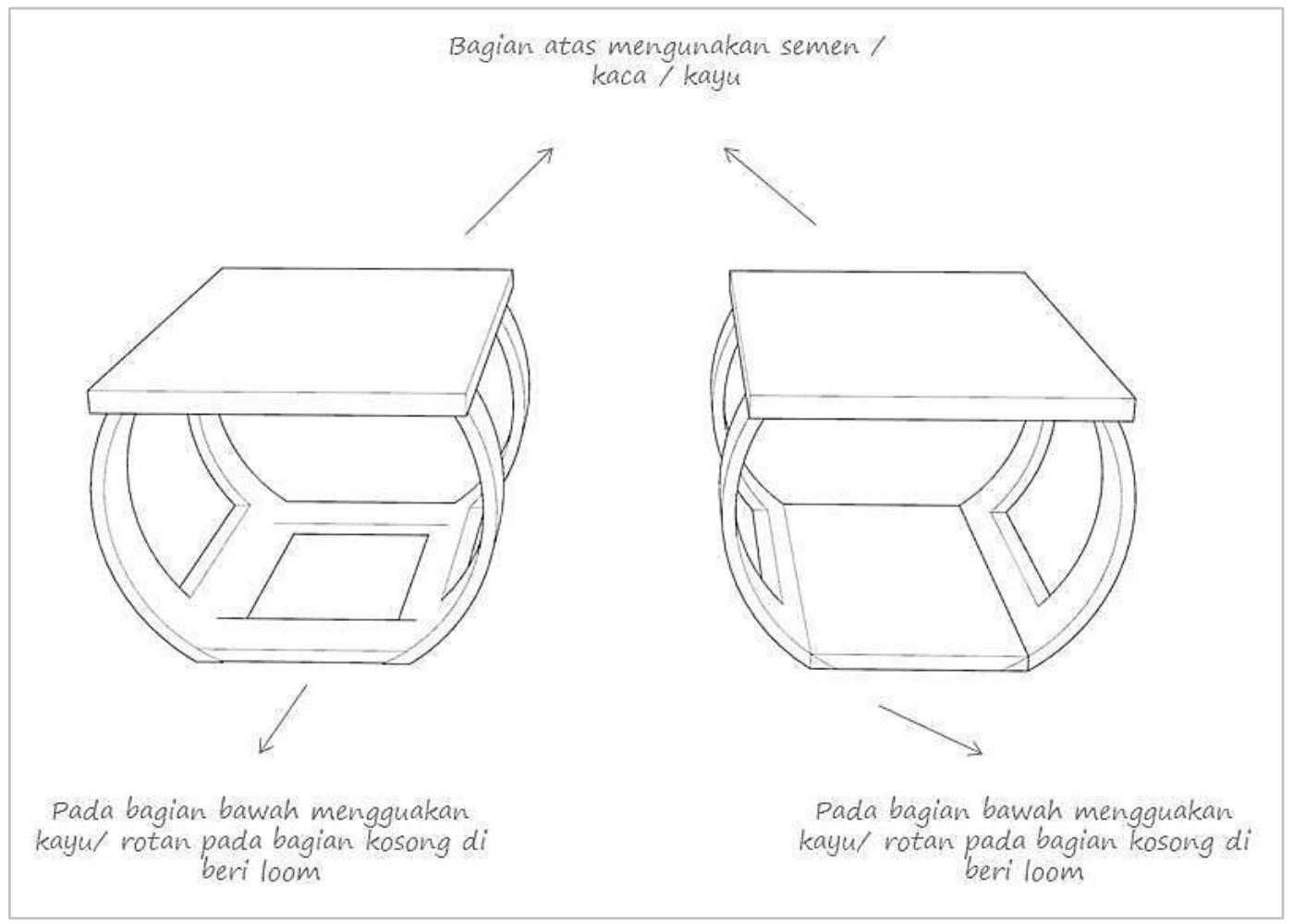

Gambar 5 Ilustrasi Pemanfaatan sebagai Meja 3 - Loom dalam rangka kayu/ rotan (Sumber : dokumen pribadi, 2017)

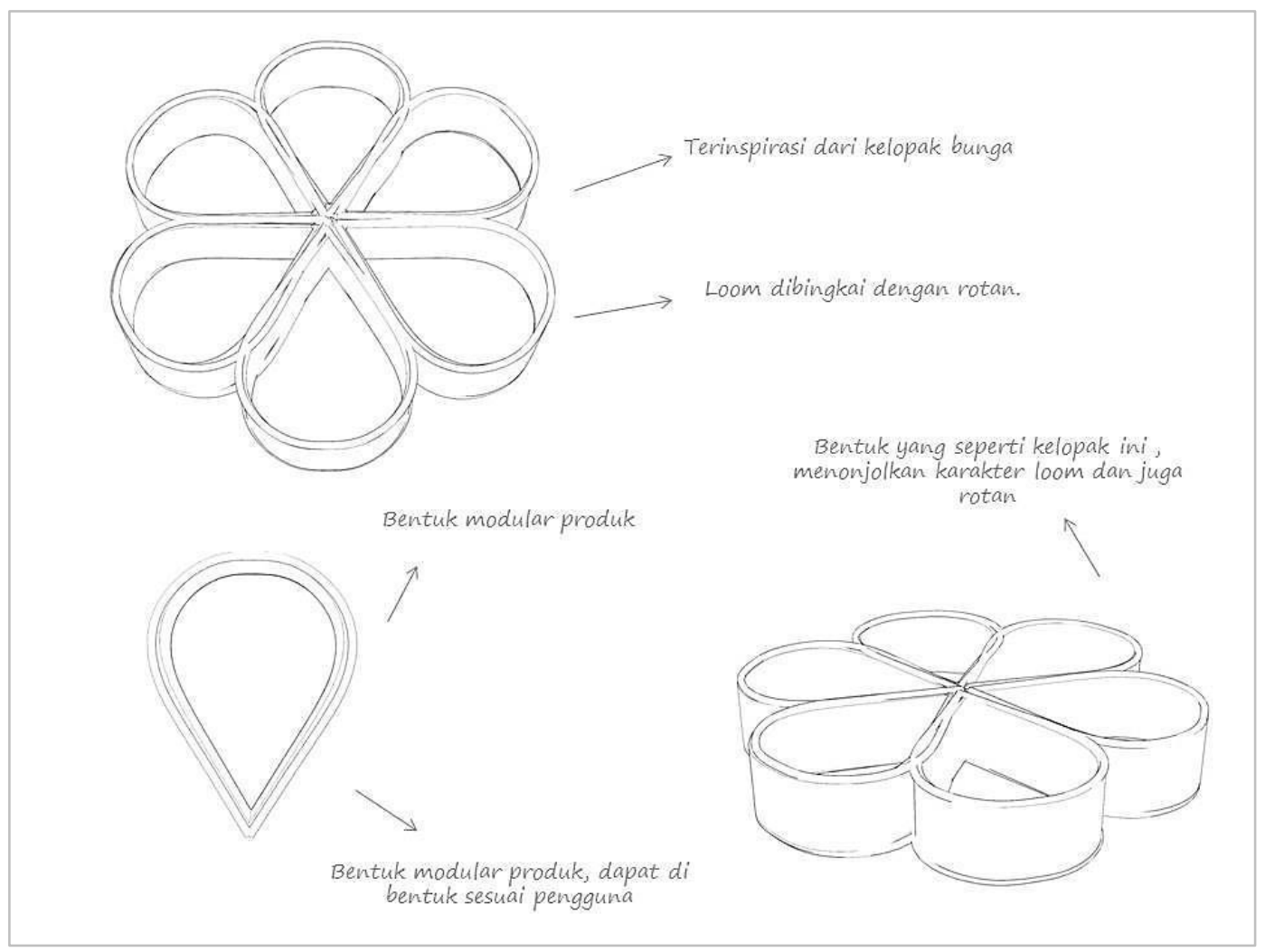

Gambar 6 Ilustrasi Pemanfaatan sebagai Meja 4 - Loom dalam rangka rotan

(Sumber : dokumen pribadi, 2017) 

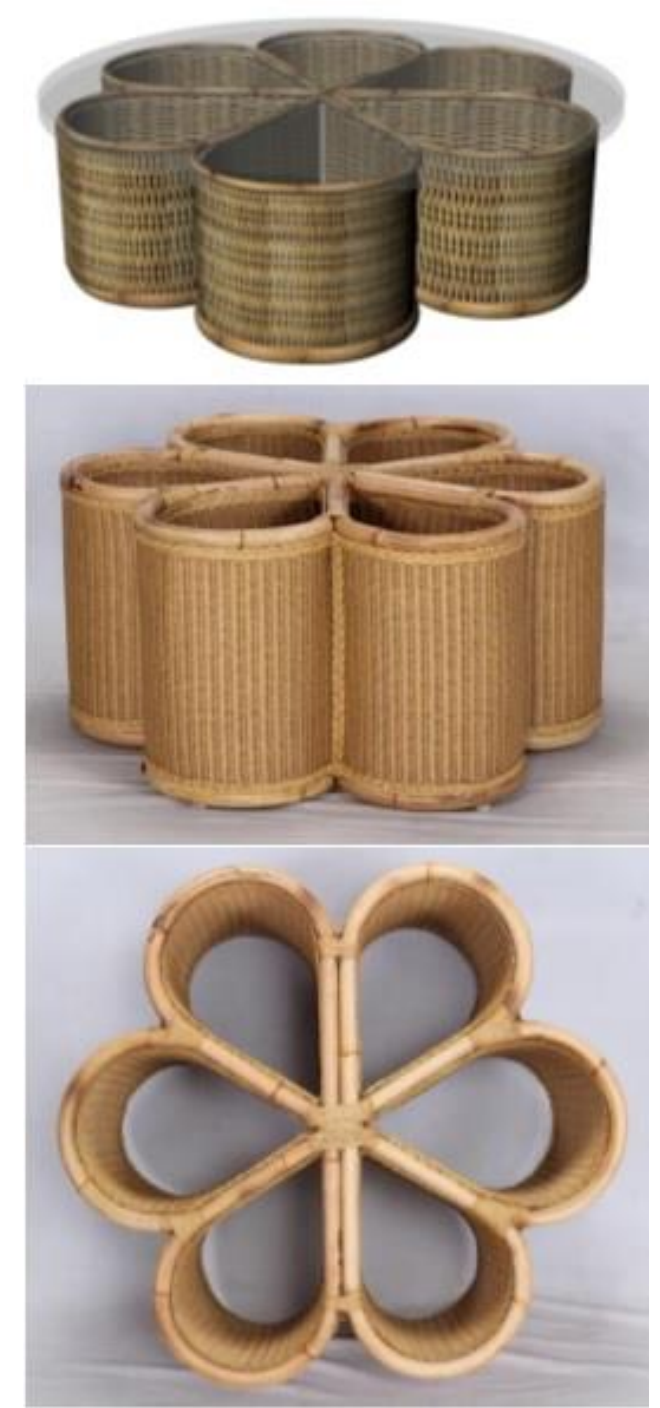

Gambar 7 Render \& Prototipe Rekomendasi Meja 4 (Sumber : dokumen pribadi, 2017)

Dari 4 rekomendasi, meja 4 dinilai yang paling memaksimalkan penggunaan loom dengan material pendukung paling sedikit. Gabungan modul ini juga bisa diaplikasikan untuk produk lain seperti standing lamp atau table lamp.

\section{REFERENSI}

House of Rattan, Cirebon CV Property, Cirebon
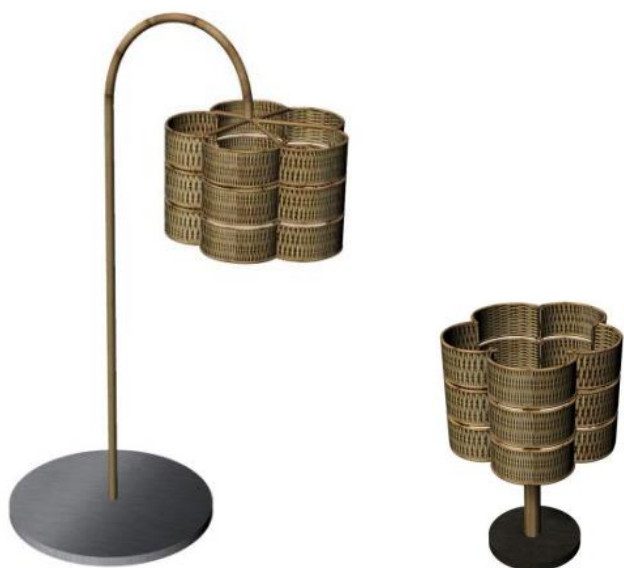

Gambar 8 Opsi Produk Lain untuk Rekomendasi 4 (Sumber : dokumen pribadi, 2017)

\section{SIMPULAN}

Rekomendasi pemanfaatan baru terbatas pada loom ukuran besar, namun dengan pemanfaatan maksimal (tidak menggunakan banyak material pendukung). Sayangnya, volume limbah loom berukuran besar tidak sebanyak yang berukuran kecil. Belum ada penerapan produk mebel untuk limbah loom berdimensi kecil (10-20 $\mathrm{cm}$ dari sisi panjang atau lebar) karena terbatas kendala konstruksi. Konstruksi dalam furniture merupakan salah satu aspek desain yang tidak boleh salah perhitungan. Walaupun demikian, limbah berukuran kecil sangat besar potensinya untuk produk home décor atau aksesoris, mengingat minimnya aspek konstruksi yang perlu dipertimbangkan. Topik ini sangat bisa dikaji lagi untuk penelitian selanjutnya.

\section{Buku:}

Yamakawa,Y. "Product Design Development : Rattan 
Furniture Design".Makalah

dalam JICA In-Country

Training di Cirebon, 7

Novermber 2000.

\section{Internet:}

Ecolenefiber. "Ecoloom", http://ecolenefiber.com/produc t/ecoloom/. Diakses pada 17 Maret 2017.

Lloyd Loom."Lloyd Loom History", http://www.lloyd-

loom.co.uk/history/.Diakses pada tanggal 17 Maret 2017. 